\title{
Acute Lymphoblastic Leukemia Presenting as Acute Low Back Pain in a Young Man- A Case Report
}

\author{
*Islam $K A^{1}$, Hassan $M N^{2}$, Mafruha $S^{3}$, Ahmed $M^{4}$, Islam $K M K^{5}$, Kabir $A L^{6}$, Yunus ABM
}

\begin{abstract}
Here we describe a case of a 20-year-old, otherwise healthy man, who consulted a physician due to acute low back pain presenting for a couple of days. Pain appeared suddenly, without any preceding trauma. Physical examination was unremarkable. Initial laboratory tests showed elevated inflammatory marker and thrombocytopenia. Patient was treated conservatively but due to increasing pain MRI of spine with contrast was advised which showed feature suggestive of inflitrative disease. Eventually patient was diagnosed as a case of acute lymphoblastic leukaemia on further peripheral blood film and bone marrow study.
\end{abstract}

Key words: acute lymphoblastic leukaemia, low back pain, leukaemic infiltration.

\section{INTRODUCTION:}

Acute lymphoblastic leukaemia (ALL) is a malignant tumor of haemopoietic progenitor cell of lymphoid lineage of mostly unknown etiology. Though it is most common malignancy in children but rare leukaemia in adults (0.7-1.8/100000 annually) 1 . It is commonly presented with the features of bone marrow failure like weakness due to

1.*Dr. Khaza Amirul Islam,MD phase-B resident, Department of Haematology, Bangabandhu Sheikh Mujib Medical University, Dhaka, Email:

khazaamirulislamrubel@gmail.com

2. Dr. Nazmul Hassan, Assistant Professor, Department of Internal Medicine Bangabandhu Sheikh Mujib Medical University, Dhaka.

3. Dr. Sharmin Mafruha, MD phase-B resident

,Department of Haematology, Bangabandhu Sheikh Mujib Medical University, Dhaka.

4. Dr. Munim Ahmed, Medical Officer, Department of Haematology, Bangabandhu Sheikh Mujib Medical University, Dhaka.

5. Dr. Kazi Mohammad Kamrul Islam, Research Assistant, Department of Haematology Bangabandhu Sheikh Mujib Medical University, Dhaka.

6. Dr. Amin Lutful Kabir, Associate Professor,Department of Haematology, Bangabandhu Sheikh Mujib Medical University, Dhaka.

7. Prof. Dr. A.B.M. Yunus, Professor, Department of Haematology, Bangabandhu Sheikh Mujib Medical University, Dhaka.

${ }^{*}$ Coresponding Author anaemia, bleeding manifestations due to thrombocytopenia and recurrent infections due to neutropenia. CNS, testes and gut involvement or bone pain due to marrow expansion are some other uncommon features. ALL is usually diagnosed by peripheral blood film and bone marrow examination. Low back pain is a rare symptom for ALL, but the initial hint of MRI report present with unusual lumbo-sacral spine was leaded us to present this case.

\section{CASE PRESENTATION:}

A twenty years old man presented to a physician with acute low back pain for a couple of days. Symptoms appeared suddenly and were not associated with preceding trauma. Pain was intensified especially during night and waking him from sleep. Pain was exacerbated by movement, there was no radiation, no morning stiffness and not associated with lower limb weakness. On query, he did not give any history of heavy weight lifting, fever, weakness or bleeding from any site of body.

On examination temperature was $36.5^{\circ} \mathrm{C}$, heart rate$78 / \mathrm{min}$, blood pressure- $120 / 70 \mathrm{~mm}$ of $\mathrm{Hg}$, respiratory rate 16 breath/min but no anaemia, jaundice, lymphadenopathy or bony tenderness. Examination of spine reveals movement of lumber spine restricted in all direction with mild local tenderness. There was no local deformity. Examination of SI joint was normal. CBC showed Haemoglobin- $11.4 \mathrm{gm} / \mathrm{dl}$, Platelet- $80 \times 109 / \mathrm{L}$, WBC- $8 \times 109 / \mathrm{L}$ including Neutrophil$49 \%$, Lymphocyte- $38 \%$, Monocyte- $9 \%$, Eosinophil $2 \%$, Basophil-2\% and ESR- 32mm in first hour. On peripheral blood film examination revealed no atypical cell. Inflammatory marker CRP was $138 \mathrm{mg} / \mathrm{L}$. Chest X-ray P/A view, X-ray SI joint $\mathrm{AP}$ and oblique view revealed normal finding. Patient was started on NSAID (Naproxen $250 \mathrm{mg}$ bid) and muscle relaxant (Baclofen 10mg bid), without clinical improvement rather the patient deteriorated.

As pain was deteriorating, patient was advised to do an MRI of lumbo-sacral spine with contrast which revealed diffuse marrow reconversion changes with few irregular enhancing altered signal intensities - suggestive of infiltrative disease.(Figure- 1) Then peripheral blood film was examined and bone marrow biopsy was done. Peripheral blood film showed RBC- anisocytosis with anisochromia, WBCNeutropenia with some atypical looking mononuclear cell, Platelet- Reduced. Comment- Thrombocytopenia with atypical looking cell.(Figure- 2) In bone marrow biopsy image was hyper cellular, both myeloid and erythroid series were depressed and lymphocyte were increased in number having shift to the left. About 50\% cells were atypical 
looking mononuclear cells having increase nucleo-cytoplasmic ratio, dense chromatin and most of the cells are vacuolated giving an impression of acute lymphoblastic leukaemia (ALL).(Figure- 3) On flow cytometry- cells were CD 79a +, CD 19+, HLADR +.So patient diagnosed as a case of $\mathrm{B}$ cell linage acute lymphoblastic leukaemia. Unfavorable prognostic fusion gene BCR-ABL was negative but full panel of cytogenetic study could not be done due to financial constrain.

Adult BFM protocol was planned for treatment, meanwhile patient became icteric. On examination patient had firm, smooth hepatomegaly. Workup for jaundice reveled $S$. bilirubin (total) $5.31 \mathrm{mg} / \mathrm{dl}, \mathrm{S}$. bilirubin (direct) $4.91 \mathrm{mg} / \mathrm{dl}$, SGPT- 62.18 U/L, SGOT- $215.75 \mathrm{U} / \mathrm{L}$, Alkaline Phosphatase- $468.48 \mathrm{U} / \mathrm{L}$, prothrombin time- 12 s. All the viral markers were negative. Ultrasonography of Hepatobiliary system revealed hepatomegaly with prominent periportal echo. Due to financial constrain complete evaluation of jaundice such as liver biopsy, MRCP, CT scan of abdomen could not be done. As per available supporting evidence we consider leukaemic infiltration of liver or obstruction of biliary channel at porta hepatis by enlarged lymph node as the cause of jaundice. So we start BFM protocol in compromised dose. Though there was initial rise of hepatic enzymes, but ultimately liver function improved.

After giving compromised dose of induction chemotherapy due to impaired hepatic function patient is now in partial bone marrow remission status(Figure-4) but liver function improves (Table-I).

Table- I. Evolution of liver function tests.

\begin{tabular}{|l|c|c|c|c|c|c|c|}
\hline & $8-4-17$ & $20-4-17$ & $30-4-17$ & $6-5-17$ & $15-5-17$ & $31-5-17$ & $22-6-17$ \\
\hline S. Bilirubin (mg/dl) & 4.91 & 22.65 & 7.97 & 4.15 & 3.01 & 1.33 & 0.74 \\
\hline SGPT(U/L) & 62.18 & 244.29 & 88.31 & 114.11 & 97.73 & 77.89 & 51.81 \\
\hline SGOT(U/L) & 215.75 & 161.2 & 53.70 & 62.34 & & 34.79 \\
\hline Alk. Phosphatase(U/L) & 468.24 & 326.5 & 498.68 & 578.50 & 434.83 & 373.04 & 162.04 \\
\hline
\end{tabular}

\section{DISCUSSION:}

Typical clinical picture of hematological malignancy is in the form of pale skin and mucous membrane, weakness, fever, bruising, bleeding, bone pain, abdominal pain or lymphadenopathy may mimic other disease2. On the other hand low back pain is a common symptom in adult usually mechanical but may also be a presentation of ALL.

Atypical presentation as well as normal blood picture in early routine test may lead to delay in diagnosis2. Leukemia should always be considered in patients with unexplained pain in the back or of the epiphysis of the long bones, or joint pain out of proportion to the severity of existing arthritis when there is no history of trauma .3,4 Such patient often pose a significant diagnostic dilemma for physician. Frequently they received NSAIDs with lack of clinical improvement and subsequent symptoms including weakness, loss of appetite and bruising led to blood test, which often reveals profound anemia and severe thrombocytopenia. This led to undue delay in diagnosis. Here in this case, patient present with only low back pain and initial PBF was normal but MRI of lumbo-sacral spine with contrast gives the clue of marrow infiltrative disease and ultimately BMS reveals the diagnosis.

For the treatment of ALL cytotoxic chemotherapy are used which have significant hepatotoxic properties. So, normal liver function is a prerequisite for treatment. Though a postmortem study showed liver infiltration in $>95 \%$ of ALL but it is usually mild and clinically silent at the time of diagnosis5, 6. Jaundice may occur after starting chemotherapy due to hepatotoxicity, but before starting of chemotherapy jaundice may develop if there is preexisting chronic liver disease, viral hepatitis, massive leukaemic infiltration or obstruction of biliary channel due to enlarge lymph node at porta hepatis7. In case of later two liver function should improve after chemotherapy due treatment response which we observe in this case.

\section{LIST OF FIGURES:}

Figure-1: MRI of lumbosacral spine showing irregular marrow enhancement.

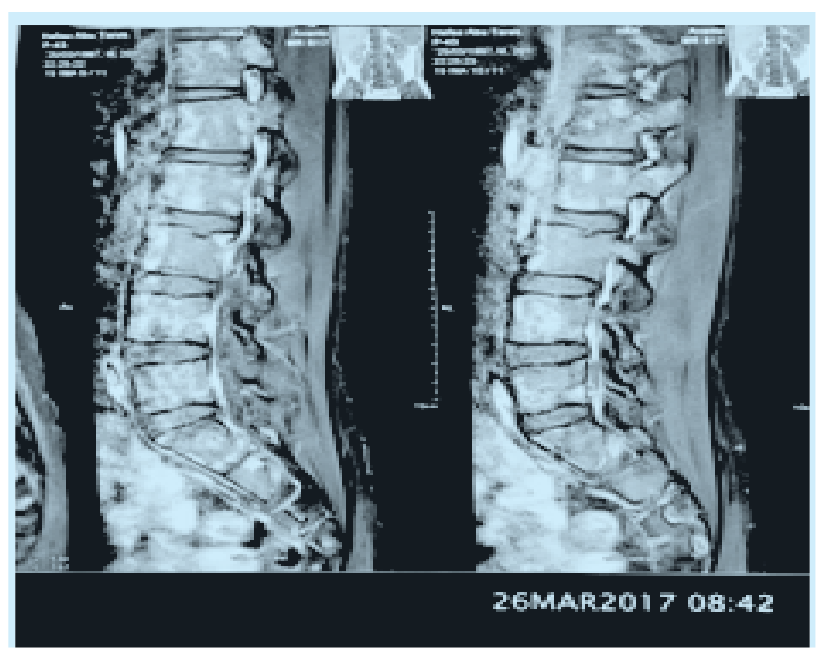


Figure -2: peripheral blood film showing atypical looking atypical looking mononuclear cells.

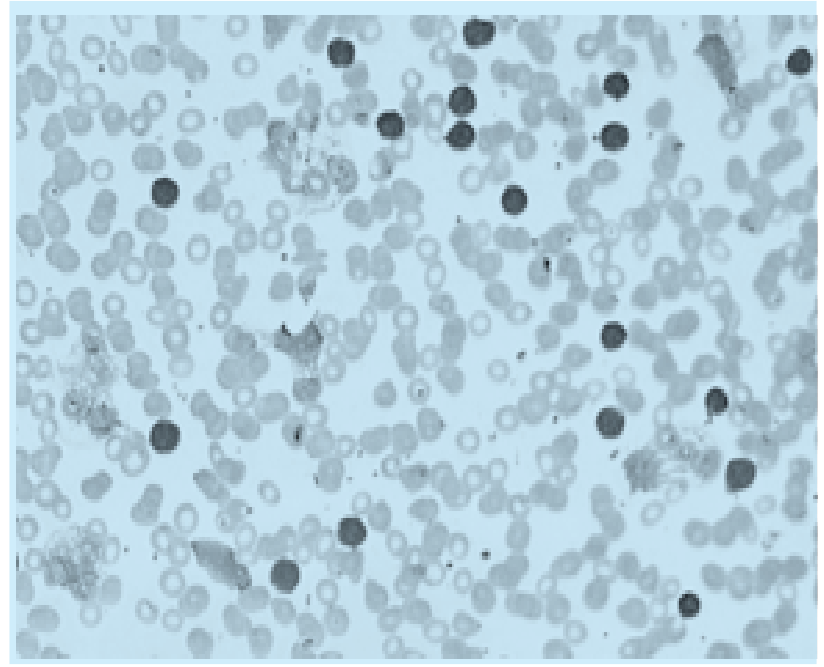

Figure -3: Bone marrow biopsy showing $>50 \%$ cells are lymphoblast (before treatment)

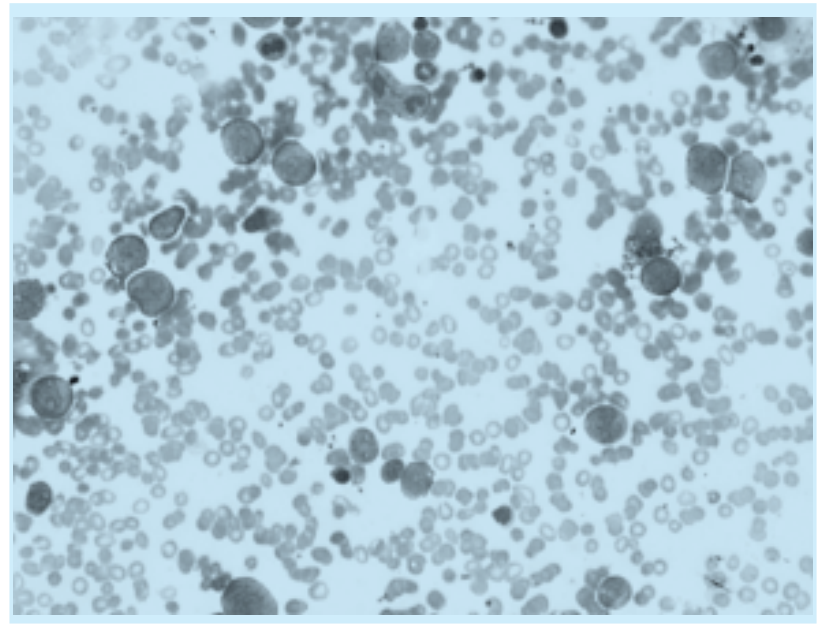

Figure- 4: Bone marrow in partial remission after induction therapy.

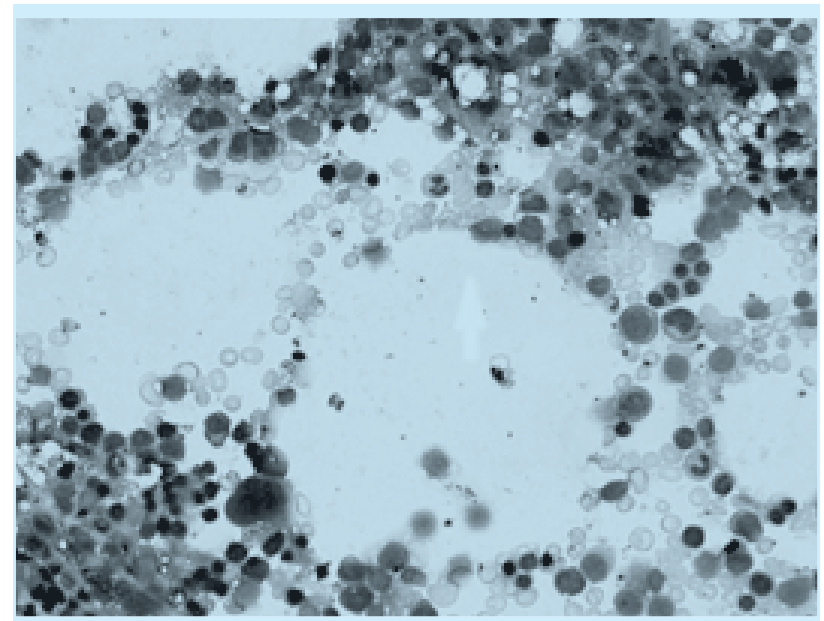

\section{REFERENCES}

1. Provan D, Baglin T, Dokal I, Vos Jd. Oxford handbook of clinical haematology, 4th ed. Oxford: Oxford university press;2015. p. 138.

2. Szudy A, Litak J, Zawitkowska J, Kowalczyk J. Back pain as a first symptom of hematologic malignancy in a 9-year-old girl. Pediatr Pol 2012;

87(1): 95-8

3. Schaller J, Wedgwood RJ. Juvenile rheumatoid arthritis: a review. Pediatrics 1972; 50: 940-53.

4. Tuten HR, Gabos PG, Kumar SJ et al. The limping child: a manifestation of acute leukemia. J. Pediatr. Orthop. 1998; 18: 625-9.

5. M. Bruguera and R. Miquel, "The effect of hematological and lymphatic diseases on the liver," in Textbook of Hepatology, J. Rod'es, J. P. Benhaumou, A. T. Blei, J. Reichen, and M. Rizzetto, Eds., p. 1662, Blackwell,Oxford, UK, 3rd edition, 2007.

6. D. L. Thiele, "Hepatic manifestations of systemic disease and other disorders of the liver," in Sleisenger \& Fordtran's Gastrointestinal and Liver Disease, M. Feldman, L. S. Friedman, and M H. Sleisenger, Eds., p. 1603, Elsevier Science, Philadelphia, Pa, USA, 7th edition, 2002.

7. CESUR S, Topcuoglu P, Asik O, Birengel S, Ozcan M. Acute Hepatic Failure in a Case of Acute Lymphoblastic Leukemia. Turk J Med Sci. 34 (2004): 275-9. 